\title{
Downregulation of Foxo3 and TRIM31 by miR-551b in side population promotes cell proliferation, invasion, and drug resistance of ovarian cancer
}

\author{
Zhentong Wei $^{1}$ - Yan Liu ${ }^{2}$ - Yishu Wang ${ }^{3}$ Yandong Zhang ${ }^{6}$ Qinghua Luo ${ }^{2}$. \\ Xiaxia Man $^{1} \cdot$ Feng $\mathrm{Wei}^{5} \cdot$ Xiaowei $\mathrm{Yu}^{1,4}$
}

Received: 4 July 2016/Accepted: 5 October 2016/Published online: 14 October 2016

(C) The Author(s) 2016. This article is published with open access at Springerlink.com

\begin{abstract}
Ovarian cancer (OVCa) stem cells are associated with tumor growth, metastasis, and recurrence, which are driving forces behind a majority of the OVCa-related mortality. This subpopulation of cancer cells are characterized by uncontrolled proliferation, high invasiveness, and resistance against the current platinum-based therapy. Thus, targeting OVCa cancer stem cells has been focused in recent therapeutic development. Isolation and purification of cancer stem cells are, however, challenging for the lack of sensitive and specific markers. In this study, we
\end{abstract}

Zhentong Wei and Yan Liu have contributed equally to this work.

Electronic supplementary material The online version of this article (doi:10.1007/s12032-016-0842-9) contains supplementary material, which is available to authorized users.

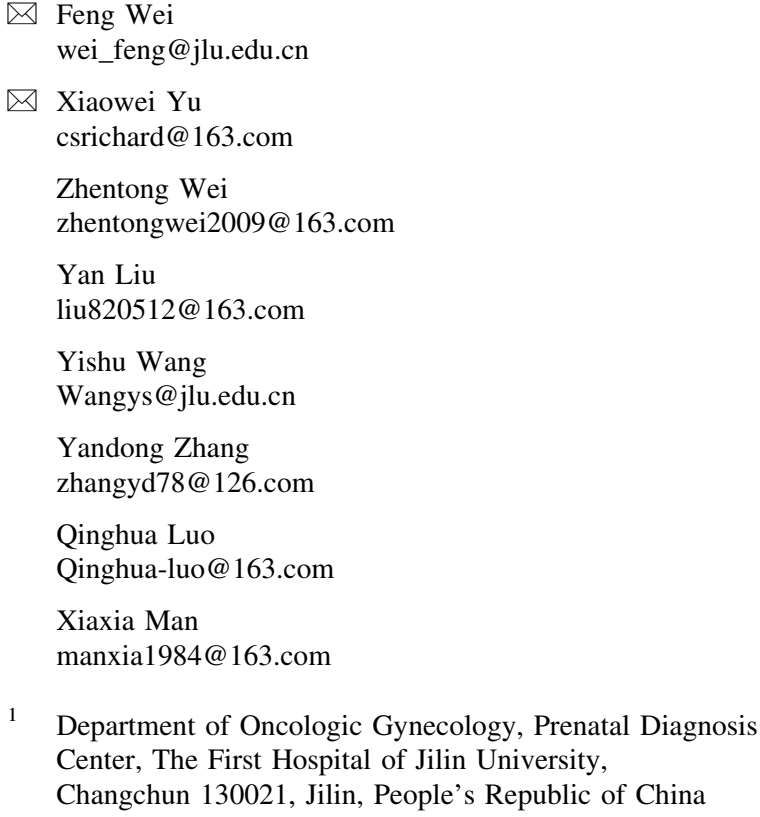

1 Department of Oncologic Gynecology, Prenatal Diagnosis Center, The First Hospital of Jilin University, Changchun 130021, Jilin, People's Republic of China

demonstrated that miR-551b was upregulated in OVCa stem cells, by using a quantitative PCR array, correlating with the pathological grades of this malignancy. In vitro experiments indicated that miR-551b promoted the proliferation, invasion, and chemoresistance of OVCa cells and cancer stem cells. Further analysis suggested that miR$551 \mathrm{~b}$ functioned through the suppression of Foxo3 and TRIM31, two important tumor suppressors. In support of this, our in vivo experiments using mouse xenograft models showed that inhibiting miR-551b significantly increased the susceptibility of OVCa cells to cisplatin and prolonged the survival of the host mice. In conclusion, our study suggested miR-551b as a potential biomarker for

2 Department of Hepatobiliary and Pancreas Surgery, The First Hospital of Jilin University, Changchun 130021, Jilin, People's Republic of China

3 The Key Laboratory of Pathobiology, The Ministry of Education, Norman Bethune College of Medicine, Jilin University, Changchun 130021, Jilin, People's Republic of China

4 Institute of Zoonotic Disease, Jilin University, Changchun 130021, Jilin, People's Republic of China

5 Genetic Engineering Laboratory of People's Liberation Army, The Eleventh Institute of Academy of Military Medical Sciences of People's Liberation Army, Changchun 130021, Jilin, People's Republic of China

6 Department of Rheumatology, The First Hospital of Jilin University, Changchun 130021, Jilin, People's Republic of China 
OVCa stem cells and explored its functional mechanism, providing a potential therapeutic target for future drug development.

Keywords Ovarian cancer - Side population of cancer cells $\cdot$ miR-551b $\cdot$ Cell proliferation $\cdot$ Cell invasion $\cdot$ Drug resistance

\section{Introduction}

Ovarian cancer (OVCa) is the most common and one of the most lethal gynecological malignancies in the world [1]. The overall 5-year survival rate has been merely 28-40\% in the past few decades [2-4]. Primary OVCa, particularly high-grade serous carcinoma that accounts for majority of this malignancy, usually responds to the first-line platinumbased chemotherapy, but the disease frequently recurs in a more aggressive form and with increased chemoresistance [1]. Although extensive studies have been performed on the recurrence and chemoresistance of OVCa in the past few decades [5, 6], the clinical outcome has not improved substantially.

Cancer stem cells (CSCs) comprise of a small number of cells with stem cell features among the highly heterogeneous mixture of various populations of cells in tumor. Characteristically, they are poorly differentiated and selfrenewable as normal stem cells and are thus capable of proliferating continuously and re-initiating tumor in vivo. CSCs play a crucial role in maintaining tumor heterogeneity and promoting cancer cell growth and metastasis [7, 8]. Moreover, they are generally less susceptible to chemotherapeutic drugs and likely the re-initiator of the recurrent cancer $[9,10]$. Therefore, identifying this subpopulation of cells and eradicating them from patients may provide an ideal opportunity to cure this disease. Indeed, targeting CSCs by interrupting PML-RAR $\alpha$ degradation and BMP4 function in animal models has significantly enhanced the regression of acute promyelocytic leukemia and brain cancer [11, 12]. Ovarian cancer is believed to be a stem cell disease. It may originate from ovarian surface epithelium stem cells or fallopian tube epithelium [13-16]. A number of biomarkers have been recommended although definitive and commonly accepted markers remain elusive $[17,18]$. Recently, a few studies isolated a side population (SP) of cells based on their exclusion of Hoechst 33342 fluorescence. These cells demonstrate extensive features of CSCs with respect to their proliferation, tumorigenicity, migration, and chemoresistance, suggesting that they can be ideal subjects in CSC studies [19]. Particularly in OVCa, independent studies have shown that SP cells isolated from fresh tumors and established cell lines are enriched with tumor-initiating cells with CSC characteristics and are highly chemoresistant $[20,21]$. In our previous study, we isolated SP cells from a primary OVCa cell line established from OVCa patient ascites and characterized their self-renewal, differentiation, and tumorigenicity [22].

microRNAs refer to a group of small noncoding RNAs which participate into the posttranscriptional gene expression control by inhibiting translation or accelerating mRNA degradation [23]. Aberrant expression of microRNAs frequently observed in multiple malignancies is associated with tumor progression [24, 25]. A good example of these is miR-551b, which is upregulated in lung squamous cell carcinoma (SCCs) and prostate cancer, and mediates tumor development and progression [26, 27]. Elevated miR-551b in OVCa enhances the resistance of cancer cells to anoikis by upregulating STAT3 and c-KIT [28].

Accumulating evidence suggests that microRNAs are pivotal for the self-renewal of CSCs and cancer metastasis and chemoresistance [29-31]; however, the underlying mechanisms are yet to be fully understood. In this study, we aimed to screen for microRNAs, which were abnormally expressed in the SP cells of OVCa in comparison with the non-SP cells. We identified miR-551b as one of the most significantly elevated microRNAs in the SP cells in comparison with the non-SP cells in OVCa. Using an miR-551b mimic or an specific inhibitor, we explored the roles of miR-551b in cell proliferation, invasion, and susceptibility to cisplatin and identified the downstream effectors. In a mouse xenograft model, miR-551b was targeted to confirm the regulatory roles of miR-551b in OVCa progression and characterize the potentiality of targeting miR-551b in future therapeutic development.

\section{Materials and methods}

\section{Patient samples}

Benign and malignant OVCa tissues and ascites fluids were collected from Department of Obstetrics and Gynecology, the First Hospital of Jilin University with written consents from all patients. All protocols involving human specimens were approved by the Human Ethics Committee of the First Hospital of Jilin University. Detailed diagnostic and pathological reports were collected for all patients, and none of them had been previously treated with chemotherapy.

\section{Cell culture, isolation of SP cells, and transfection}

Primary OVCa cells were isolated from the ascites of an ovarian serous cystadenocarcinoma patient and maintained 
as previously described [22]. Briefly, primary ascitic cells were harvested by centrifugation at $300 \mathrm{~g}$ for $5 \mathrm{~min}$, and red blood cells removed by $1 \times$ BD lysis buffer (BD Biosciences, Franklin Lakes, NJ) on ice for $1 \mathrm{~min}$, followed by centrifugation at $300 \mathrm{~g}$ for $3 \mathrm{~min}$. Primary cells were cultured for 3 weeks in a Dulbecco's modified Eagle's medium (DMEM, Invitrogen, Carlsbad, CA) supplemented with $10 \%$ fetal bovine serum (FBS), and the floating cells were collected and re-cultured. This ascites-derived OVCa cell line was established by continuous propagation. HEK293T cells were grown in DMEM supplemented with $10 \%$ FBS (Invitrogen). All cells were cultured at $37^{\circ} \mathrm{C}$ in a humidified atmosphere with $5 \% \mathrm{CO}_{2}$ in the presence of penicillin (100 units/ml) and streptomycin (100 units/ml). The cisplatin-resistant cell line was established as described previous [32]. Briefly, cisplatin-sensitive SK-OV-3 and 8910 cells parental cells were exposed to gradually increasing concentration of cisplatin (LC laboratories) from the initial $1 \mu \mathrm{M}$ to final $60 \mu \mathrm{M}$ over a 6-month period.

To isolate the SP cells, the primary ascites-derived OVCa cells were trypsinized, pelleted, and re-suspended at $1.0 \times 10^{6}$ cells $/ \mathrm{ml}$ in DMEM containing $2 \%$ flow cytometry staining buffer (BD Biosciences) and incubated at $37{ }^{\circ} \mathrm{C}$ for $10 \mathrm{~min}$. The cells were then labeled with $5 \mu \mathrm{g} /$ $\mathrm{ml}$ Hoechst 33342 dye (Invitrogen) at $37^{\circ} \mathrm{C}$ for $80 \mathrm{~min}$, followed by counterstaining with $1 \mu \mathrm{g} / \mathrm{ml}$ propidium iodide. A total of 100,000 cells were sorted on a BD Influx system, and data were processed by BD FACSDiva software (version 6.1.1, BD Biosciences).

Cells were transfected in an Opti-MEM medium (Invitrogen) with miR-551b mimic, miR-551b inhibitor, scramble RNA (GeneCopoeia, Rockville, MD) or psiCHECK-2 plasmid (Promega, Madison, WI) using Lipofectamine 2000 (Invitrogen), following the manufacturer's instructions. Cells were collected and analyzed $48 \mathrm{~h}$ after transfection.

\section{Cell proliferation assay}

Cells were seeded into 96-well plates at 3000 cells/well and cultured for $24 \mathrm{~h}$. The medium was then replaced with $10 \mu \mathrm{l}$ of cell counting kit (CCK)-8 reagent (Dojindo Laboratories, Kumamoto, Japan) and $100 \mu$ of HEPES-buffered DMEM medium (Invitrogen) containing $10 \%$ FBS. After another $2.5 \mathrm{~h}$ of culture at $37^{\circ} \mathrm{C}$, cell viability was assessed by measuring the absorbance of individual wells at $450 \mathrm{~nm}$. Five replicates were performed for each group.

\section{Colony formation assay}

Capacities of cells to form colonies were determined by two approaches. In the monolayer colony formation assay, 500 single cells were seeded into $35-\mathrm{mm}$ dishes and cultured for 10 days with medium refreshed every 3 days. At measurement, the medium was discarded, cells were stained with crystal violet $(0.1 \%$ in $20 \%$ methanol) and imaged under a SZX12 phase-contrast microscope (Olympus, Tokyo, Japan), and colonies counted.

Soft agar colony formation assay was performed following a protocol used elsewhere with limited modifications. Briefly, $500 \mu \mathrm{l}$ of $0.5 \%$ agar (Sigma-Aldrich, St. Louis, MO) prepared in appropriate cell culture medium was aliquoted into 24 -well plates $(500 \mu \mathrm{l} /$ well $)$ and allowed to solidify. On the top of this, $500 \mu \mathrm{l}$ of cell suspension at $2.66 \times 10^{2}$ cells $/ \mathrm{ml}$ prepared in $0.3 \%$ agar was added. The cells were cultured for 3 weeks, with medium refreshed twice a week, before the colonies larger than $75 \mu \mathrm{m}$ in diameter or containing more than 50 cells were counted under the microscope.

\section{RNA isolation and qPCR}

RNA from cells and tissues was isolated with a Trizol reagent (Invitrogen) following the manufacturer's instructions and used as templates in the synthesis of the firststrand complementary DNA using a TaqMan microRNA reverse transcription kit (Applied Biosystems, Foster City, CA). qPCR was performed in triplicate using a TaqMan universal PCR master mix (Applied Biosystems). The thermal cycling conditions included a 10-min denaturation at $95{ }^{\circ} \mathrm{C}$ followed by 35 cycles of 15 -s denaturation at $95^{\circ} \mathrm{C}, 1$-min annealing at $60{ }^{\circ} \mathrm{C}$, and 45 -s extension at $72{ }^{\circ} \mathrm{C}$.

\section{Western blotting}

Total proteins from cells and tissues were isolated with a RIPA buffer (Cell Signaling Technology, Danvers, MA) in the presence of a protease inhibitor cocktail (Thermo Scientific), separated by sodium dodecyl sulfate-polyacrylamide gel electrophoresis (SDS-PAGE), and transferred onto polyvinylidene fluoride (PVDF) membranes. After blocking with $5 \%$ bovine serum albumin for $1 \mathrm{~h}$ at room temperature, the membranes were incubated overnight at $4{ }^{\circ} \mathrm{C}$ with primary antibodies against Foxo3, TRIM31, and GAPDH (Cell Signaling Technology) and then for $1 \mathrm{~h}$ at room temperature with appropriate horseradish peroxidaseconjugated secondary antibodies (Abcam, Cambridge, UK). The signals were detected with an enhanced chemiluminescence detection kit (Thermo Scientific).

\section{Construction of the plasmids and dual luciferase reporter assay}

The reverse complementary miR-551b (rcmiR-551b), the wild-type and mutant $3^{\prime}$-untranslated regions (UTR) of 
Foxo3 and TRIM31 were synthesized by TaKaRa (Shanghai, China) and inserted into psiCHECK-2 or pcDNA 3.1 vectors. The restriction enzymes and T4 DNA ligase were purchased from New England Biolabs (Ipswich, MA). The sequences were confirmed by Sanger sequencing at Comate Bioscience (Changchun, China).

The dual luciferase reporter assay was performed using HEK293T cells in 24-well plates. The cells were cotransfected with $0.8 \mu \mathrm{g} / \mathrm{well}$ of plasmid and $30 \mathrm{nM}$ of miR$551 \mathrm{~b}$ mimic or its inhibitor and incubated for $24 \mathrm{~h}$. The samples were then analyzed using a dual luciferase reporter assay kit (Promega), and the assays were performed in triplicate and repeated three times.

\section{Cell cycling profiling}

Cells were synchronized by serum starving for $24 \mathrm{~h}$ and then transfected with miR-551b mimic, inhibitor, or the scramble RNA. After $48 \mathrm{~h}$, cells were detached, fixed in $70 \%$ ethanol, and stained with propidium iodide before being analyzed for cell cycle profiles by flow cytometry using a FACSCanto II system (BD Biosciences). The results were processed using a FlowJo data processing software (FlowJo, Ashland, OR).

\section{Cell invasion assay}

Cell invasion was assessed by using a BioCoat Matrigel invasion chamber (BD Biosciences). The 24-well plate was fit with inserts, which were sealed with $8-\mu \mathrm{m}$ membranes at the bottom, and the inserts were pre-coated with Matrigel. To examine cell invasion, cells were serum starved for $24 \mathrm{~h}$ and added into the top chamber at $1 \times 10^{4}$ cells in $100 \mu \mathrm{l}$ serum free medium, while $600 \mu \mathrm{l}$ medium with $1 \% \mathrm{FBS}$ was added to the bottom. After culturing for $12 \mathrm{~h}$ at $37{ }^{\circ} \mathrm{C}$, the medium in the insert was decanted, and cells and Matrigel were carefully removed with a cotton swab. Cells attached to the outside of the insert were stained with DAPI and imaged and counted under a microscope. Ten regions of interest (magnification, $40 \times$ ) were counted for each group.

\section{Mouse xenograft assay}

All protocols using animals were approved by the Institutional Animal Care and Use Committee of Jilin University. Six-week-old female SCID mice (Shanghai Laboratory Animal Centre, Shanghai, China) were inoculated subcutaneously with $3 \times 10^{4} \mathrm{SP}$ cells premixed with Matrigel at a 1:1 ratio. After the tumors were established for 2 weeks, the mice were treated by intratumoral injection of $5 \mu \mathrm{l}$ of $5 \mathrm{nM}$ agomir, $20 \mathrm{nM}$ antagomir, or saline twice a week for 4 weeks. In a second approach to examine the tumor growth in peritoneal cavity, the SP cells re-suspended in saline were injected intraperitoneally at $5 \times 10^{4}$ cells/ mouse, and the intraperitoneal administration of agomir or antagomir (twice a week for 4 weeks) began after the tumors were established.

Twenty mice were used for each group. Ten of them were used to generate the survival curve, whereas the other 10 were killed 6 weeks after inoculation. Tumor tissues were excised, weighed, and further used in qPCR and Western blotting analyses.

\section{Statistical analysis}

Data are presented as mean \pm standard error of the mean (SEM), which was obtained from a minimum of three repeats of each experiment. Data processing was performed using a GraphPad Prism 5 software (GraphPad, La Jolla, CA), and Student's $t$ test and one-way analysis of variance (ANOVA) were used to estimate the significance of difference, and $p<0.05$ was considered significant.

\section{Results}

\section{miR-551b is elevated in OVCa}

To identify microRNAs aberrantly expressed in the OVCa SP cells in comparison with the non-SP cells, the expression of 16 microRNAs was quantified by qPCR array analysis performed by Shanghai Biotechnology Corporation (Shanghai, China). In the results, miR-551b was one of the top 10 microRNAs that were upregulated in the OVCa SP cells compared to the non-SP population. This result was validated by a separate qPCR analysis for miR-551b (Fig. 1a). Consistent with this, significantly higher levels of miR-551b were detected in tissues from the advanced serous OVCa than the early stage (Fig. 1b), suggesting the association of miR-551b expression with OVCa progression. Furthermore, miR-551b was significantly upregulated in the recurrent serous OVCa compared to the primary tumors (Fig. 1c), and the cisplatin-resistant cells expressed more miR-551b than the susceptible cells (Fig. 1d), correlating with its overexpression in the stem cell-enriched SP cells, which are believed to drive tumor recurrence.

\section{miR-551b promotes the proliferation and invasion of OVCa cells}

The cellular roles of miR-551b were characterized by in vitro assays using the primary OVCa cell line established in house. Cells were transfected with miR-551b mimic, miR-551b inhibitor, or the scramble RNA, and the changes in the expression of miR-551b were confirmed by qPCR (Fig. 2a). As a result, upregulating $\operatorname{miR}-551 \mathrm{~b}$ expression led to 

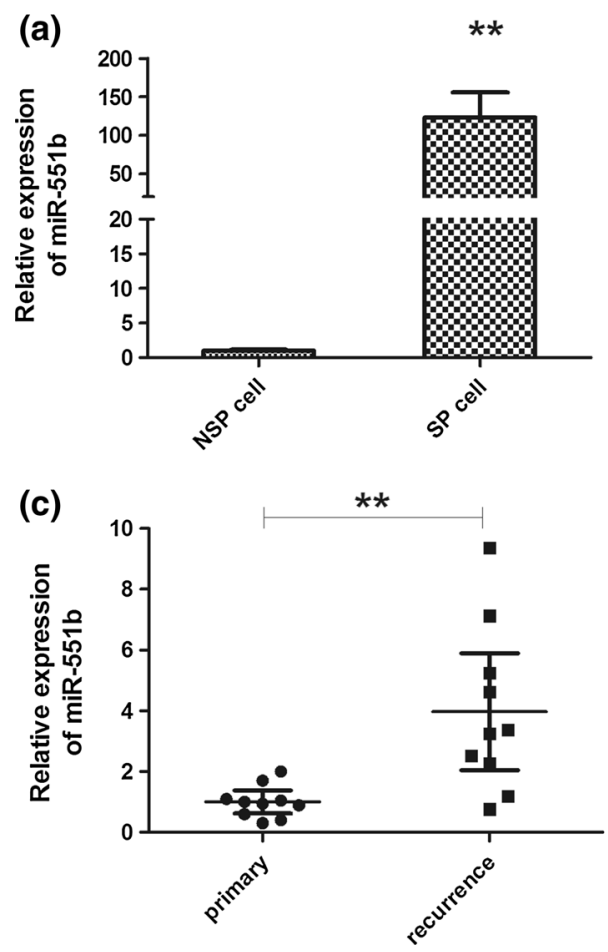

Fig. $1 \mathrm{miR}-551 \mathrm{~b}$ is upregulated in the side population of an ascitesderived OVCa cell line, and its expression correlates with the stage, recurrence, and chemoresistance of OVCa. a qPCR analysis indicates a higher level of miR-551b in the side population of the ascitesderived OVCa cell line than the non-side population, $\mathbf{b}$ expression of miR-551b in ovarian serous cystadenocarcinoma tissues with varied

significant increase in cell proliferation, while cells with miR-551b inhibitor showed no difference from the scramble transfected cells (Fig. 2b). Similar results were obtained in the monolayer colony formation assay (Fig. 2c). The enhancement of cell proliferation by miR-551b was supported by the profiling of the cell cycle. In Fig. 2d, flow cytometry analysis demonstrated that increased miR-551b reduced the cell population in the G1 phase while increasing that in the $\mathrm{S}$ phase, suggesting that this microRNA may promote the transition from $\mathrm{G} 1$ to $\mathrm{S}$ phase.

The invasion potential of cells transfected with miR$551 \mathrm{~b}$ mimic, miR-551b inhibitor, or the scramble RNA was examined by a transwell system in which the inserts were pre-coated with a layer of Matrigel. The results indicated a significant increase in the number of cells migrating through Matrigel when the primary OVCa cells were transfected with miR-551b mimic, whereas those with miR-551b inhibitor showed no apparent difference, compared to the cells with the scramble control (Fig. 2e).

\section{miR-551b promotes the colony formation of the SP cells and confers them chemoresistance}

To further dissect the functions of miR-551b in OVCa cells, we sorted out the SP cells from the ascitic OVCa cell
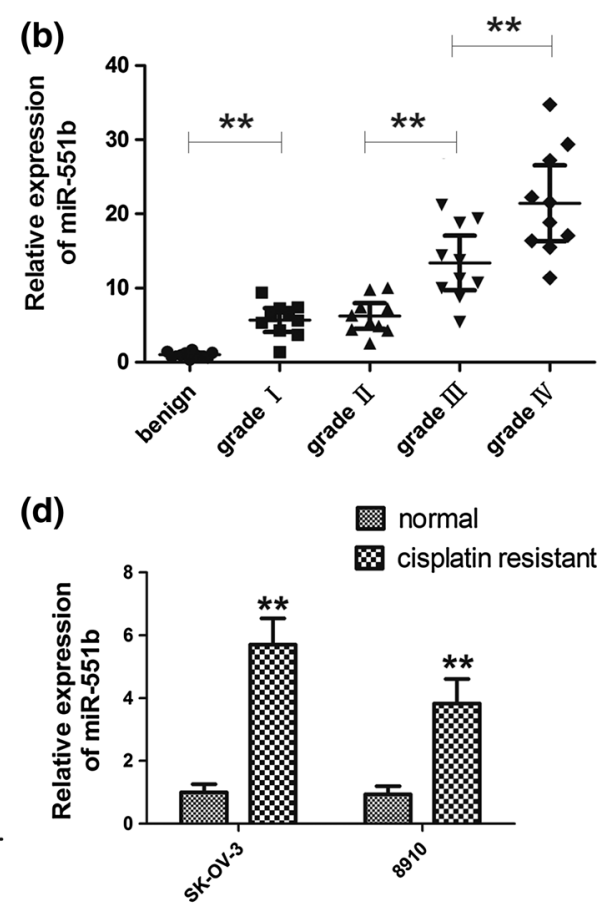

levels of differentiation was examined by qPCR, in comparison with ovarian serous cystadenoma. Ten patients were included in each group, c expression of miR-551b in the primary (Stage III) and recurrent OVCa. Samples from 10 patients were examined in each group. ${ }^{* *} p<0.01, \mathbf{d}$ expression of miR-551b was compared between the cisplatin-sensitive and cisplatin-resistant OVCa cells. ${ }^{*} p<0.01$

population and performed the soft agar colony formation assay after manipulating their miR-551b expression (Fig. 3a). The results indicated that the SP cells transfected with miR-551b mimic produced more colonies than the scramble control (Fig. 3b). Consistently, SP cells transfected with miR-551b mimic had a smaller G1 but a larger $S$ population of cells than those treated with the scramble RNA (Fig. 3c). More importantly, in these primary CSCs, inhibiting miR-551b expression using a sequence-specific inhibitor (Fig. 3a) dramatically reduced the colony formation capacity (Fig. 3b), and these data were correlated with a significantly larger $\mathrm{G} 1$ but a smaller $\mathrm{S}$ population of SP cells treated by miR-551b inhibitor (Fig. 3c).

Cancer stem cells are believed to be crucial in the chemoresistance of cancer due to their less responsiveness to the current platinum-based therapy [20,33]. We thus further characterized whether miR-551b was involved in the chemoresistance of OVCa. The SP cells transfected with miR-551b mimic, miR-551b inhibitor, or the scramble RNA were exposed to a range of doses of cisplatin, and their viability assessed after 3 days. The results demonstrated a decreased susceptibility of cells treated with miR$551 \mathrm{~b}$ mimic to cisplatin and an increased responsiveness of cells with miR-551b inhibitor (Fig. $3 \mathrm{~d}$ ). The $\mathrm{IC}_{50}$ values for cells with the scramble RNA, miR-551b mimic, and 
(a)

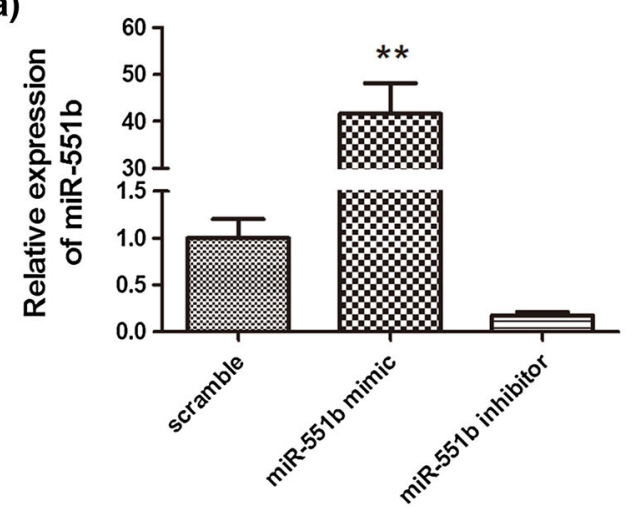

(c)

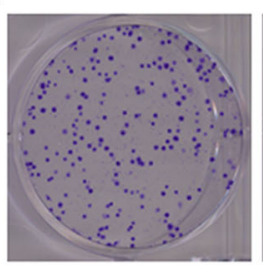

scramble

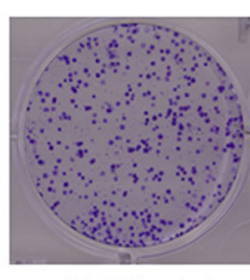

miR-551b mimic

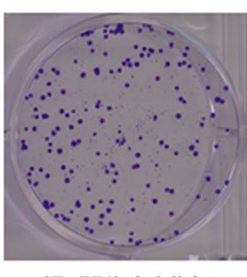

miR-551b inhibitor
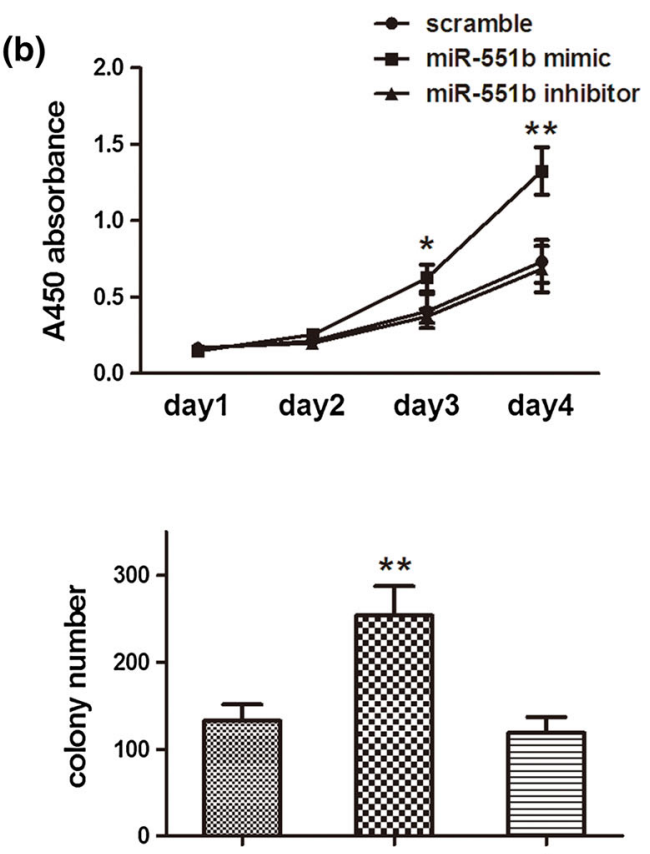

(d)
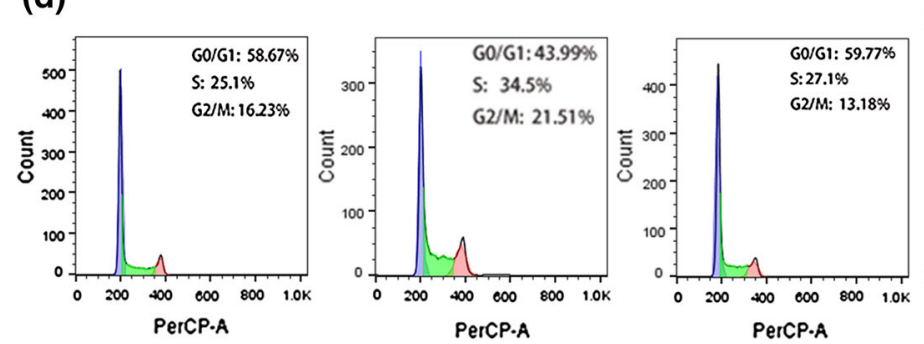

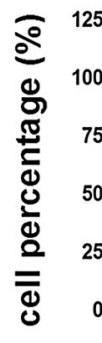

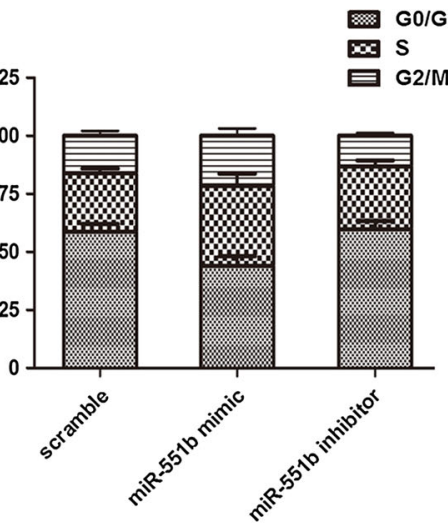

(e)

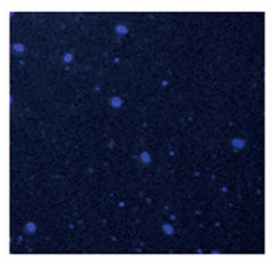

scramble

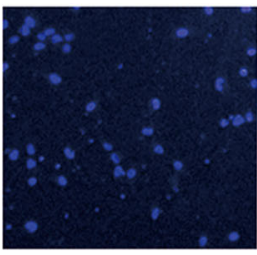

miR-551b mimic

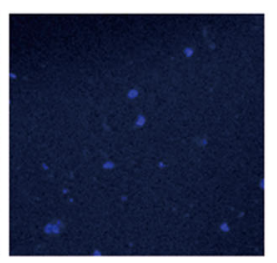

miR-551b inhibitor

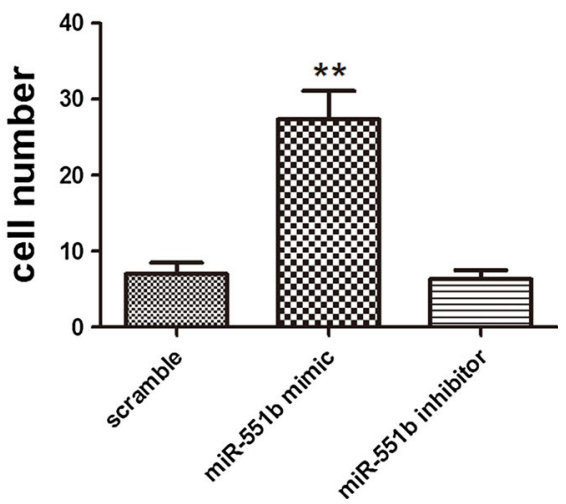


4Fig. 2 miR-551b promotes the proliferation and invasion of OVCa cell lines. a Expression of miR-551b was manipulated by transfecting cells with miR-551b mimic or miR-551b inhibitor, using scramble RNA as a control, and the expression of miR-551b was examined by qPCR, b miR-551b significantly enhanced cell proliferation as assessed by a CCK- 8 assay, c monolayer colony formation of cells transfected with miR-551b mimic or miR-551 inhibitor was compared to the scramble control, $\mathbf{d}$ cell cycle profiles were determined by flow cytometry, and the results presented as percentages of cells in G0/G1, $\mathrm{S}$, and $\mathrm{G} 2 / \mathrm{M}$ phases, e cells with upregulated miR-551b expression showed enhanced invasion through Matrigel in a transwell system. Cells migrated through the Matrigel layer were stained with DAPI and imaged under a fluorescence microscope, scale bar $100 \mu \mathrm{m}$. Results are averaged from three repeats of all experiments. $* * p<0.01 ; * p<0.05$
miR-551b inhibitor were 2.33, 3.41, and $1.49 \mu \mathrm{g} / \mathrm{ml}$, respectively.

\section{Identification of the downstream targets of miR- $551 b$}

We next asked how miR-551b executes its important functions in the proliferation, invasion, and chemoresistance of OVCa cells. Using three microRNA target prediction algorithms, including TargetScan, Pictar, and microRNA, we found that Foxo3 and TRIM31 were among the potential targets of miR-551b. The potential targeting sequences are shown in Fig. 4a. Foxo3 encodes one of the
Fig. 3 miR-551b increases the invasion of the SP cells from the ascites-derived OVCa cell line and enhances their chemoresistance. miR-551b expression was quantified by qPCR after the SP cells were transfected with miR-551b mimic, miR-551b inhibitor, or scramble RNA control (a). Colony formation of these cells in soft agar was then assessed (b), and cell cycle profiles determined by flow cytometry (c). The susceptibility of cells to chemotherapeutic drug was assessed by exposing them to $0.5-8 \mu \mathrm{g} / \mathrm{ml}$ cisplatin for 3 days and measuring their viability by a CCK-8 assay. $\mathrm{IC}_{50}$ values were calculated using GraphPad Prism 5.0 software. Data were averaged from three repeats of all experiments. $* p<0.05$ (a)

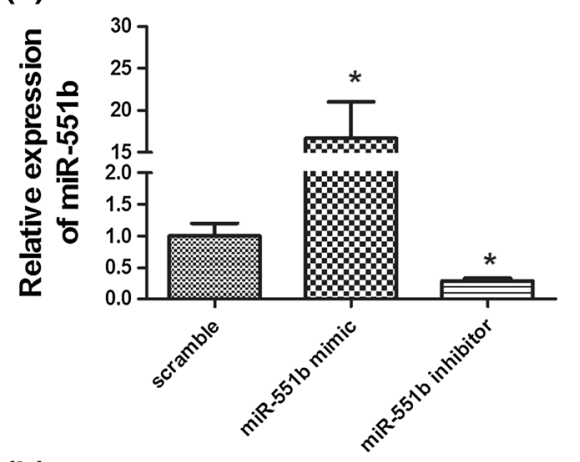

(b)

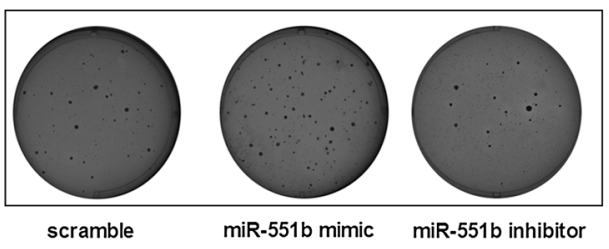

(d)

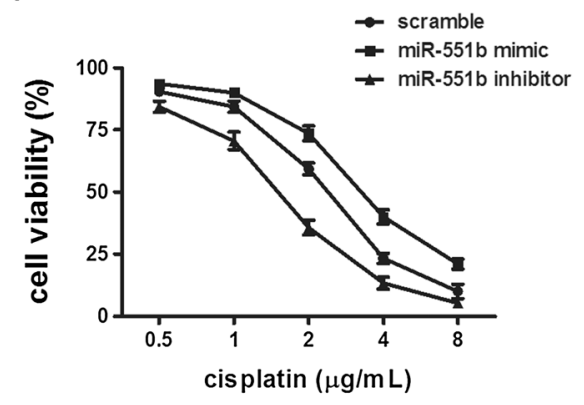

(c)
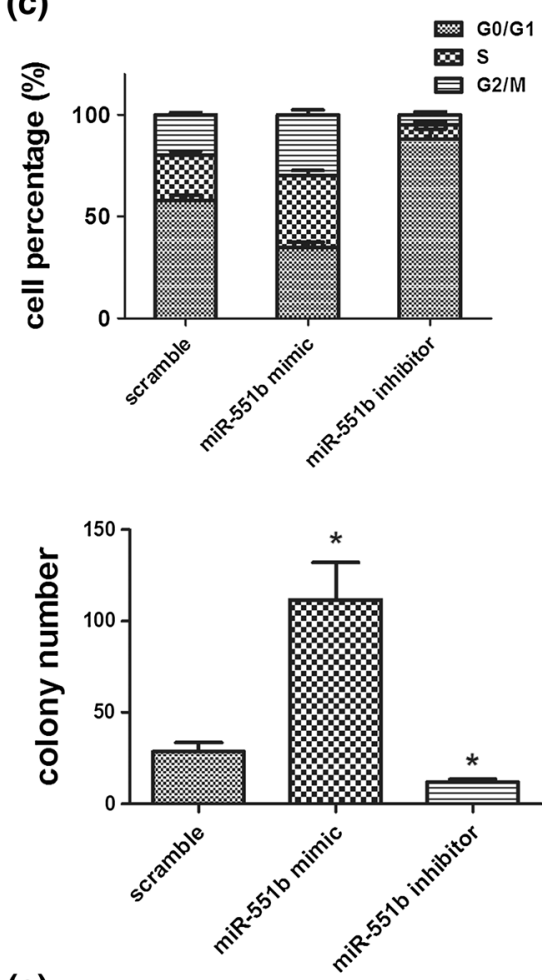

(e)

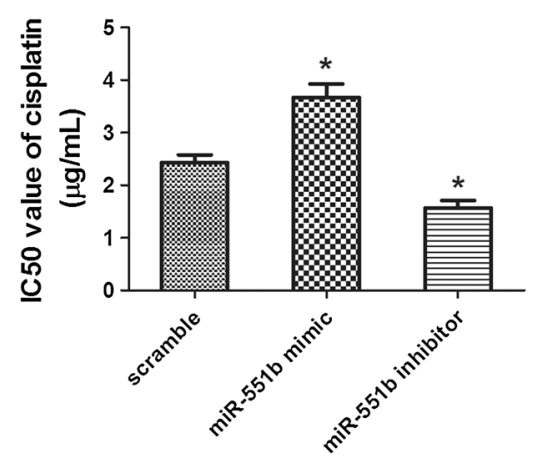


fork head family of transcription factors, which control the expression of multiple apoptosis regulating factors, such as p53 and p21 [34]. TRIM31 is a member of the tripartite motif family of proteins featured by RING finger, B-box, and coiled-coil domains. It is downregulated in multiple malignancies, correlating with tumor stage and metastasis [35], while its overexpression suppresses c-Src-induced cell growth by interacting with p52 [36].

To validate the mediation of Foxo3 and TRIM31 by miR-551b, we performed a dual luciferase reporter assay to assess the interaction of miR-551b with the wild-type and mutant $3^{\prime}$-UTRs of Foxo3 and TRIM31 using the empty psiCHECK-2 vector and rcmiR-551b as controls (Fig. 4b). The results showed that miR-551b mimic significantly inhibited the expression of Foxo3 and TRIM31, while miR$551 \mathrm{~b}$ inhibitor led to no obvious change (Fig. 4c, d). These results were supported by qPCR and Western blotting analyses of TRIM31 and Foxo3, respectively, using the SP cells from OVCa (Fig. 4e). When the targeting sequences in the $3^{\prime}$-UTRs were mutated, the miR-551b-mediated effects were completely abolished (Fig. 4c, d), suggesting the interaction of miR-551b with the $3^{\prime}$-UTRs of Foxo3 and TRIM31.

To define whether Foxo3 and TRIM31 are involved in the miR-551b-mediated cellular functions, Foxo3 or TRIM31 was overexpressed in OVCa cells in the presence or absence of miR-551b mimic (Supplemental Fig. 1A). Cell proliferation assay demonstrated that miR-551b significantly promoted, consistently with our data in Fig. 2b, while exogenous Foxo3 and TRIM31 inhibited cell proliferation (Supplemental Fig. 1B, C). Importantly, both Foxo3 and TRIM31 apparently abrogated the induction of proliferation by miR-551b when either was co-transfected with miR-551b (Supplemental Fig. 1B, C). Flow cytometry analysis showed that the cells were arrested at G0/G1 phase when Foxo3 or TRIM31 was overexpressed (Supplemental Fig. 1D). The two proteins counteracted against miR-551b and negated the increase in $\mathrm{S}$ phase cells population caused by this microRNA (Supplemental Fig. 1D). Moreover, exogenously expressed Foxo3 or TRIM31 also overturned the increase in cell invasion induced by miR-551b (Supplemental Fig. 1E). These data suggested that miR-551b regulates the proliferation and invasion of the OVCa SP cells through its inhibitive effect on the expression of Foxo3 and TRIM31.

\section{Targeting miR-551b increases the susceptibility of mouse xenografts to cisplatin}

Mouse xenograft model was employed to confirm our in vitro observations, which suggested key roles of miR-551b in the proliferation and invasion of OVCa cells. The SP cells were inoculated subcutaneously into the flanks of SCID mice, and the established tumors were treated by intratumoral injection of agomir or antagomir of miR-551b to up- or downregulate miR-551b levels. At harvest after 4 weeks of treatment, miR-551b agomir increased the tumor burden by $42 \%$, compared to the controls which were injected with saline, while miR-551b antagomir decreased the tumor burden by $38 \%$ (Fig. 5a). Corresponding to this, mice treated with miR-551b agomir survived for a shorter period than the control, while the treatment with miR-551b antagomir prolonged the survival (Fig. 5b).

In support of the mediation of Foxo3 and TRIM31 by miR-551b observed in vitro, Western blotting analysis revealed that the expression of Foxo3 and TRIM31 was inhibited in tumors treated by miR-551b agomir and enhanced in those by miR-551b antagomir (Fig. 5c). The data suggested that the mediation of Foxo3 and TRIM31 by miR-551b was occurring in vivo and might play a key role in the observed impacts of miR-551b on tumor growth (Fig. 5a).

Our in vitro data in Fig. 3d suggested that miR-551b mediated the resistance of the SP cells against cisplatin. We therefore tested whether this conclusion stands in an in vivo model. The freshly isolated SP cells were injected intraperitoneally into SCID mice and allowed to form tumors. Mice were treated by intraperitoneal administration of miR-551b agomir, miR-551b antagomir, or saline, together with $25 \mathrm{mg} / \mathrm{kg}$ cisplatin. When the mice were killed after 4 weeks of treatment, higher tumor burdens were measured in mice co-injected with miR-551b agomir and cisplatin than those with saline and cisplatin (Fig. 5d). On the other hand, mice co-administrated with miR-551b antagomir and cisplatin grew significantly fewer tumors (Fig. 5d), and as a result, these mice survived much longer periods than the other two treatment groups (Fig. 5e).

\section{Discussion}

In this study, we screened for microRNAs aberrantly expressed in the SP cells isolated from an ascites-derived OVCa cell line in comparison with the non-SP cancer cells. miR-551b was identified as one of the top 10 upregulated microRNAs in the SP cells. Further in vitro and in vivo assays suggested that miR-551b mediated the proliferation, invasion, and chemoresistance, likely through its control over the expression of Foxo3 and TRIM31.

Majority of the experiments in the study were performed using the SP cells originated from malignant OVCa ascites, which is associated with the transcoelomic metastases of OVCa cells [37, 38]. The SP populations of cells in many cancers demonstrate stem cell features although contradictive results have also been reported for certain types of cancer. The enrichment of CSCs in the SP population of 


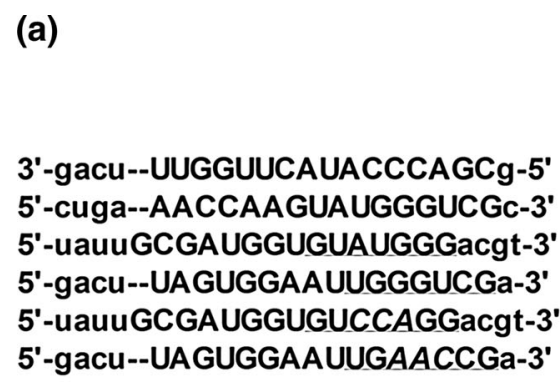

3'-gacu--UUGGUUCAUACCCAGCg-5' 5'-cuga--AACCAAGUAUGGGUCGc-3' 5'-gacu--UAGUGGAAUUGGGUCGa-3' 5'-uauuGCGAUGGUGUCCAGGacgt-3'

miR-551b rcmiR-551b

Foxo3 3'-UTR-WT TRIM31 3'-UTR-WT FOX03 3'-UTR-MUT TRIM31 3'-UTR-MUT (a)

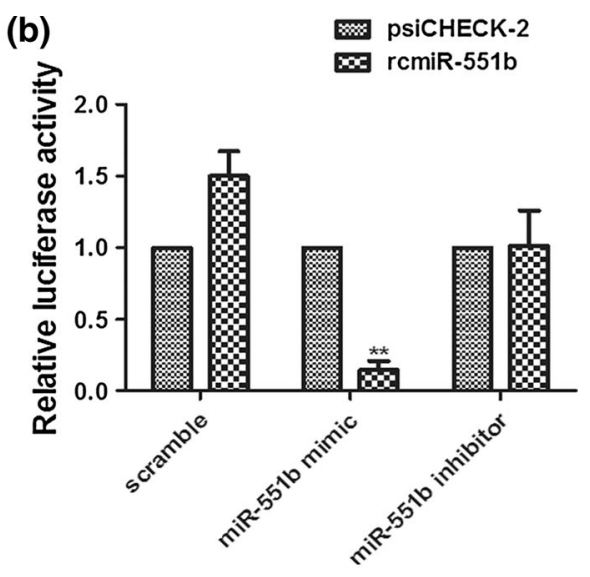

(c)
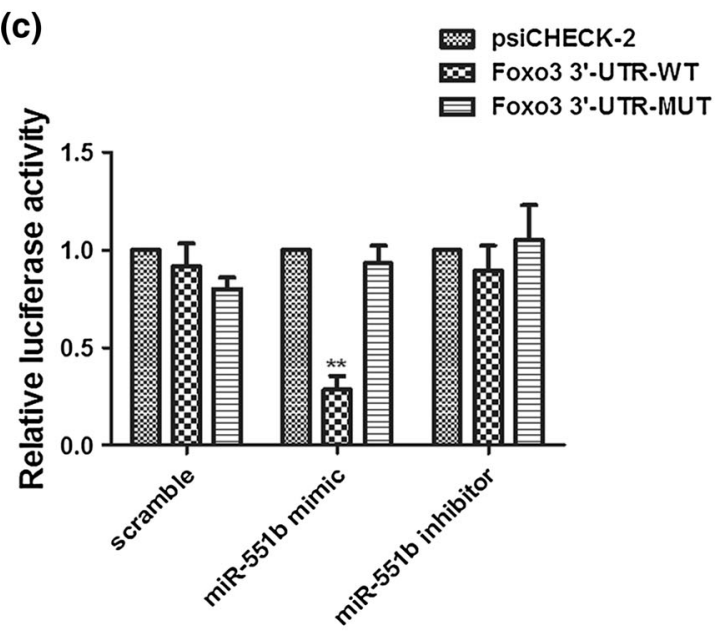

(d)

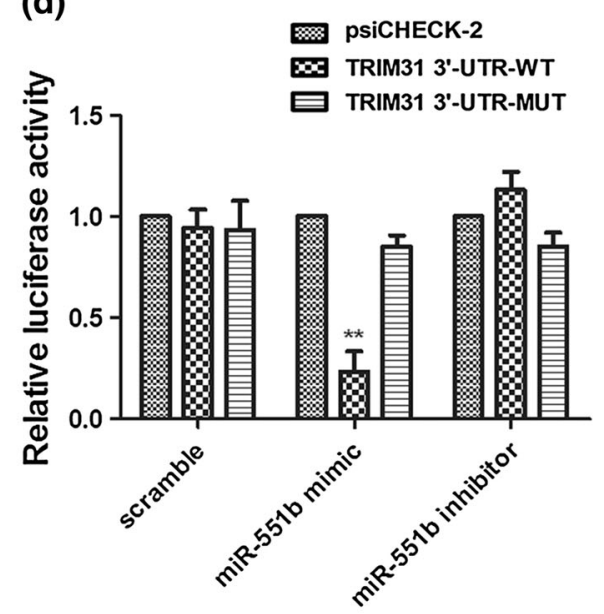

(e)
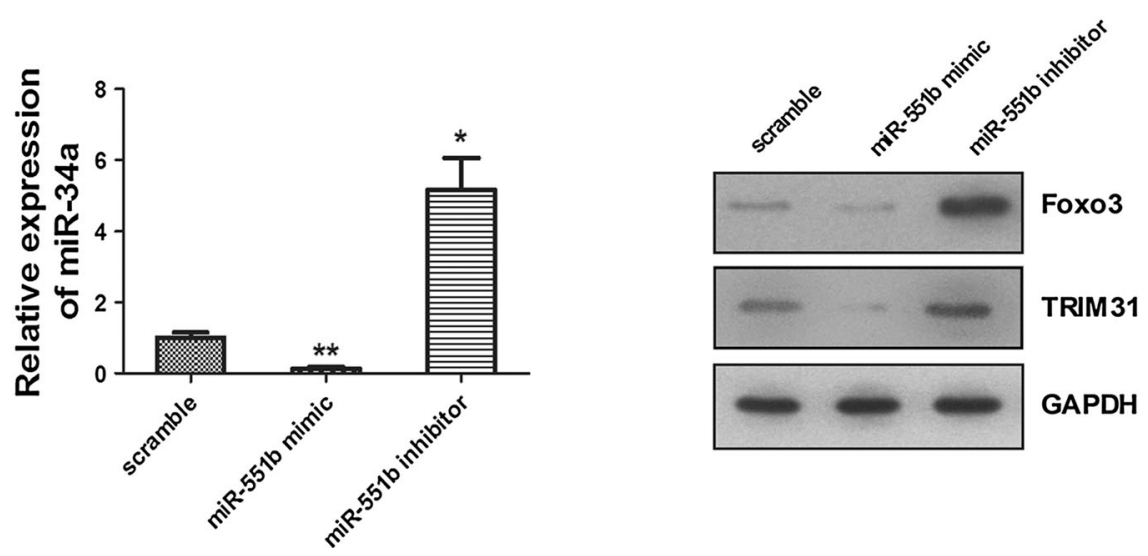

Fig. 4 Foxo3 and TRIM31 are downstream targets of miR-551b. a Sequences of miR-551b, rcmiR-551b, and the potential targeting regions in the $3^{\prime}$ UTRs of Foxo 3 and TRIM 31 are shown. In the mutant forms of Foxo3 and TRIM31, mutated nucleotides are underlined, $\mathbf{b}-\mathbf{d}$ association of miR-551b with $\mathrm{rcmiR}-551 \mathrm{~b}$, and the

OVCa cells has been confirmed by independent studies including ours $[22,39,40]$. The results from these studies establish that the SP cells of OVCa possess significant stem cell characteristics, such as cell differentiation, colony formation, tumorigenesis, and chemoresistance [22]. wild-type and mutant forms of $3^{\prime}$ UTRs of Foxo3 and TRIM31 in HEK293T cells were determined by a reporter assay. Data were averaged from three repeated experiments, e the mediation of Foxo3 and TRIM31 by miR-551b was confirmed by qPCR and Western blotting, respectively. $* * p<0.01 ; * p<0.05$

Therefore, the SP cells of OVCa can be a useful model in the development of therapeutic approaches targeting CSCs or cells with stem cell features, which are disputably the major reasons behind the progression and the acquired chemoresistance of many malignancies [41]. 
(a)

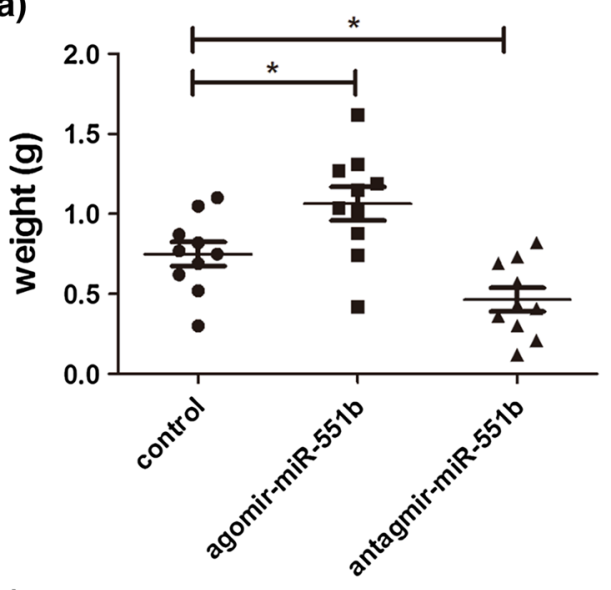

(c)

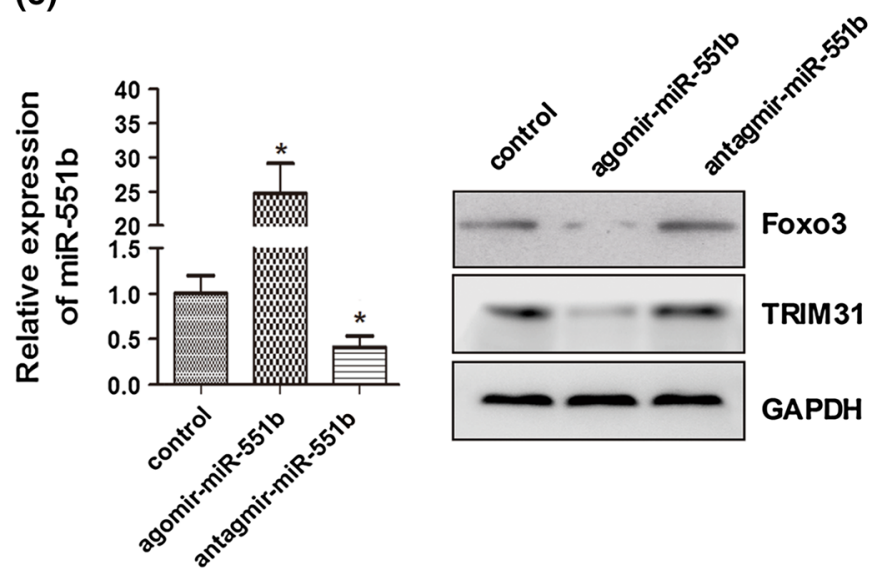

(d)

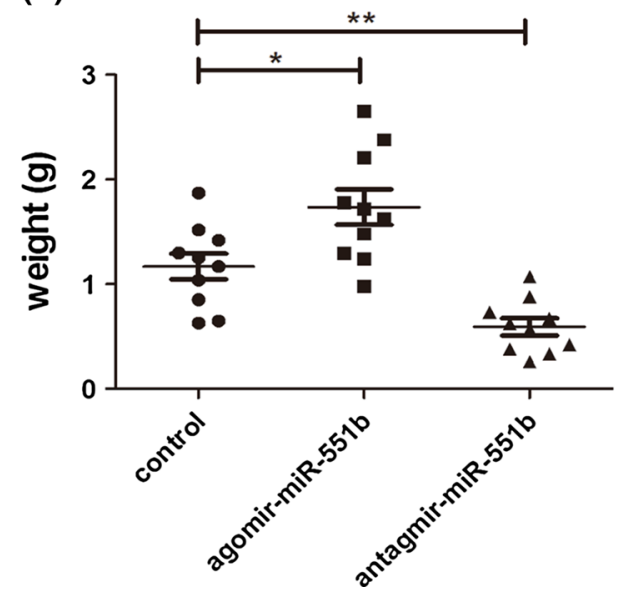

Fig. 5 Blocking the expression of miR-551b inhibits the growth of ovarian tumors in vivo. In the subcutaneous mouse xenograft models, the tumor burden in mice was significantly increased by the 4-week treatment of miR-551 agomir, but reduced by miR-551b antagomir (a), and correlated with these, mice injected with miR-551b agomir had poorer survival $(p=0.0035)$, while those with miR-551b antagomir showed better survival in comparison with the control mice (b). Expression of miR-551b, Foxo3 and TRIM31 in the
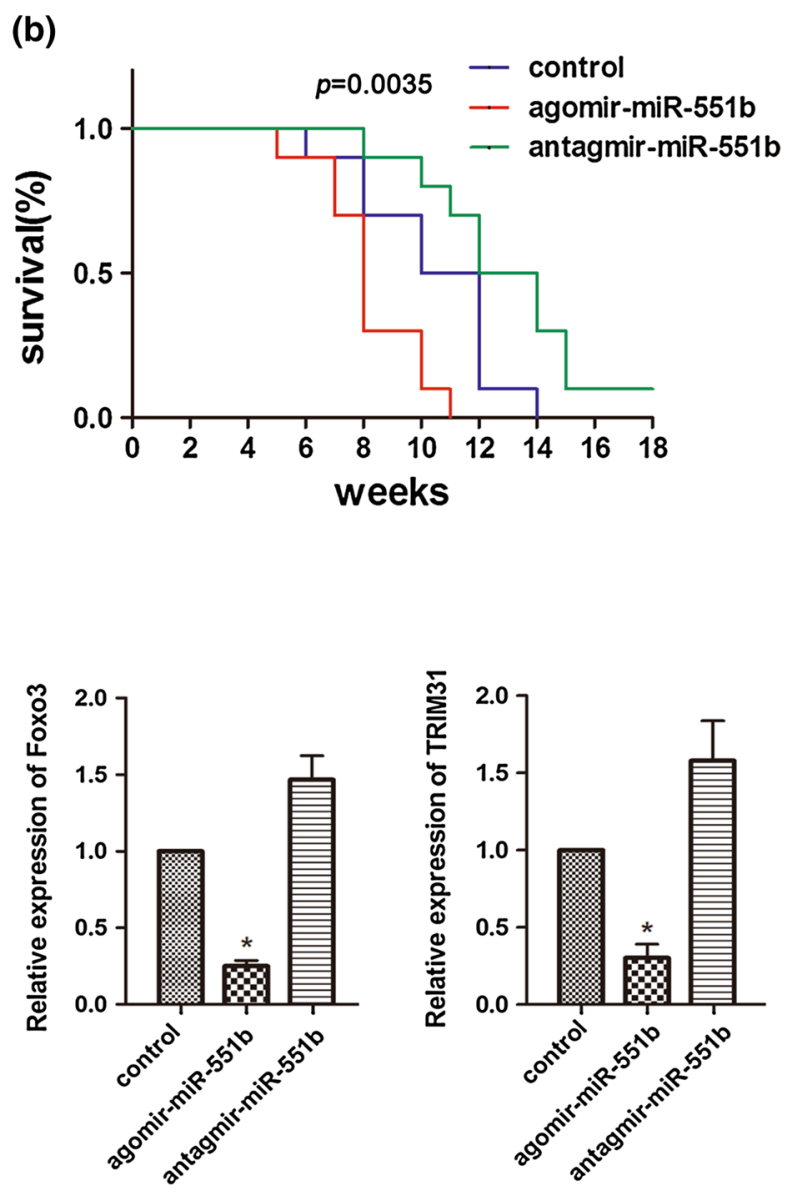

(e)

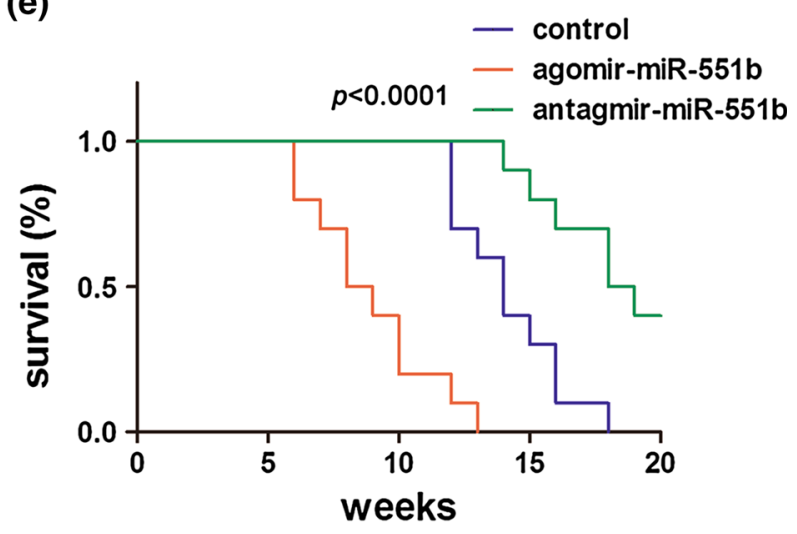

xenografts was assessed by $\mathrm{qPCR}$ and Western blotting (c). In the intraperitoneal mouse xenograft model, mice were injected intraperitoneally with SP cells and were treated for 4 weeks with miR-551b agomir, miR-551b antagomir, or the vehicle, in the presence of $25 \mathrm{mg} / \mathrm{kg}$ cisplatin (intraperitoneal delivery). Tumor burdens in mice at harvest were compared (d), and survival curves graphed (e). $* * p<0.01 ; * p<0.05$ 
Emerging evidence suggests a critical role of microRNAs in OVCa progression. Upregulation of the miR-200 family microRNAs predicts poor progression-free and overall survivals of OVCa patients [42]. On the other hand, microRNAs can be tumor suppressive. miR-7 reverses epithelial-mesenchymal transition by inactivating AKT/ ERK1/2 via EGFR and inhibits OVCa metastasis [43]. miR-9 inhibits the proliferation, migration, and invasion of serous OVCa cells by blocking TLN1-mediated FAK/AKT pathway [44]. In addition, expression of miR-496, miR152, miR-422b, and miR17-3p correlates with acquired cisplatin resistance [45]. The current study demonstrates that miR-551b is over 100-fold higher in the SP cells than in the non-SP population of cells, implicating that this microRNA is required to maintain the phenotypic features of the SP cells. Indeed, miR-551b upregulates STAT3 and c-KIT and enhances the resistance of ovarian tumor cells to anoikis [28]. This mechanism may extend to other anchorage-free settings since miR-551b expression is also enhanced in the circulating prostate cancer cells [27]. Further studies are needed to define whether miR-551b is involved in other processes important for OVCa metastases, such as spheroid formation and the colonization of OVCa cells on the surfaces of adjacent organs in the peritoneal cavity $[27,46]$.

In solid ovarian tumors, miR-551b expression correlates with tumor grades (Fig. 1b), suggesting its close association with cancer progression. This is consistent with the association of miR-551b expression with the survival of 296 OVCa patients, as demonstrated by previous microRNA profiling [47]. In addition, miR-551b expression is elevated in the recurrent OVCa compared to the primary disease (Fig. 1c) although its functional importance in OVCa recurrence is unknown. In lung cancer cells, miR$551 \mathrm{~b}$ inhibits the expression of catalase and enhances the accumulation of reactive oxygen species and the expression of mucin-1, contributing to the acquired resistance to apoptosis and chemotherapy [48].

Our data support significant roles of miR-551b in the proliferation and invasion of the ascitic SP cells in vitro and the growth of tumor xenografts in mice (Fig. 5). This is likely through the suppression of Foxo3 and TRIM31 expression as shown by the binding of miR-551b to the UTRs of Foxo3 and TRIM31 transcripts (Fig. 4) and the reversing of the miR-551 mimic-induced phenotype by exogenous Foxo3 and TRIM31 (Supplemental Fig. 1). Foxo3 is a known regulator of p53 and p21 [34], exhibiting a tumor-suppressive role in high-grade pelvic serous carcinogenesis [49]. The observed shifts of the SP cells between $\mathrm{G} 1$ and $\mathrm{S}$ phases of the cell cycle in response to the manipulation of miR-551b expression are consistent with the known functions of Foxo3 in cell cycle progression [34]. TRIM31 is aberrantly expressed in multiple cancers. It is downregulated in lung cancer with tumor stage [35], whereas its elevation in gastric carcinoma leads to inhibition of cell proliferation [50]. At molecular level, TRIM31 interacts with p52 and regulates Src kinase [50]. Our results suggest a tumor-suppressive role of TRIM31 in OVCa cells in response to miR-551b. Consistent with our in vitro observations, inhibitions of Foxo3 and TRIM31 by miR-551b were observed in mouse xenografts (Fig. 5), suggesting the occurrence of the signaling in vivo.

In summary, our results demonstrate that miR-551b is significantly higher in OVCa SP cells than the non-SP cells. Its upregulation correlates with increased proliferation and invasion of the SP cells in vitro and growth of the mouse xenografts in vivo. Moreover, our data also suggest that miR-551b contributes to the development of chemoresistance of the SP cells in vitro and in vivo, and its inhibition sensitizes cancer cells to chemotherapy, emphasizing its value in future therapeutic development. In an attempt to explore the mechanism of miR-551b functioning, we have shown that miR-551b functions through Foxo3 and TRIM31. However, further studies are required to define the mechanism that triggers its elevation in cancer and the network through which this microRNA relays its signals in its pro-cancerous functions.

Author contributions F.W. and X.-W.Y. conceived and designed the experiments; Z.-T.W, Y.-S.W., Y.L., Y.-D.Z., and Q.H.-L. performed the experiments; Y.L. and X.-X.M. analyzed the data; Z.-T. W, Y.-S.W., F.W., and Y.L. wrote the paper; all the authors have read and approved the final manuscript to be published.

Funding This study was supported by grants from the National Natural Science Foundation of China (81301884 to Yan Liu), Jilin Province Science and Technology Development Program (201405200 32JH to Zhentong Wei, 20140520036JH and 20160414052GH to Yan Liu) Bethune Project Plan B of Jilin University (450060521279 to Feng Wei).

\section{Compliance with ethical standards}

Conflict of interest All the authors declare no conflict of interest.

Ethical approval All protocols using animals were approved by the Institutional Animal Care and Use Committee of Jilin University. All procedures performed in studies involving human participants were in accordance with the ethical standards of the Human Ethics Committee of the First Hospital of Jilin University and with the 1964 Helsinki Declaration and its later amendments or comparable ethical standards.

Informed consent Informed consent was obtained from all individual participants included in the study.

Open Access This article is distributed under the terms of the Creative Commons Attribution 4.0 International License (http://crea tivecommons.org/licenses/by/4.0/), which permits unrestricted use, distribution, and reproduction in any medium, provided you give appropriate credit to the original author(s) and the source, provide a link to the Creative Commons license, and indicate if changes were made. 


\section{References}

1. Jelovac D, Armstrong DK. Recent progress in the diagnosis and treatment of ovarian cancer. CA Cancer J Clin. 2011;61(3): 183-203.

2. Coleman RL, Monk BJ, Sood AK, Herzog TJ. Latest research and treatment of advanced-stage epithelial ovarian cancer. Nat Rev Clin Oncol. 2013;10(4):211-24.

3. Vaughan S, Coward JI, Bast RC Jr, Berchuck A, Berek JS, Brenton JD, Coukos G, Crum CC, Drapkin R, Etemadmoghadam $\mathrm{D}$, et al. Rethinking ovarian cancer: recommendations for improving outcomes. Nat Rev Cancer. 2011;11(10):719-25.

4. Harrington BS, He Y, Davies CM, Wallace SJ, Adams MN, Beaven EA, Roche DK, Kennedy C, Chetty NP, Crandon AJ, et al. Cell line and patient-derived xenograft models reveal elevated CDCP1 as a target in high-grade serous ovarian cancer. Br J Cancer. 2016;114(4):417-26.

5. Cooke SL, Ng CK, Melnyk N, Garcia MJ, Hardcastle T, Temple J, Langdon S, Huntsman D, Brenton JD. Genomic analysis of genetic heterogeneity and evolution in high-grade serous ovarian carcinoma. Oncogene. 2010;29(35):4905-13.

6. Stronach EA, Alfraidi A, Rama N, Datler C, Studd JB, Agarwal R, Guney TG, Gourley C, Hennessy BT, Mills GB, et al. HDAC4-regulated STAT1 activation mediates platinum resistance in ovarian cancer. Cancer Res. 2011;71(13):4412-22.

7. Malanchi I, Peinado H, Kassen D, Hussenet T, Metzger D, Chambon P, Huber M, Hohl D, Cano A, Birchmeier W, et al. Cutaneous cancer stem cell maintenance is dependent on betacatenin signalling. Nature. 2008;452(7187):650-3.

8. O'Brien CA, Pollett A, Gallinger S, Dick JE. A human colon cancer cell capable of initiating tumour growth in immunodeficient mice. Nature. 2007;445(7123):106-10.

9. Bao S, Wu Q, McLendon RE, Hao Y, Shi Q, Hjelmeland AB, Dewhirst MW, Bigner DD, Rich JN. Glioma stem cells promote radioresistance by preferential activation of the DNA damage response. Nature. 2006;444(7120):756-60.

10. Diehn M, Cho RW, Lobo NA, Kalisky T, Dorie MJ, Kulp AN, Qian D, Lam JS, Ailles LE, Wong M, et al. Association of reactive oxygen species levels and radioresistance in cancer stem cells. Nature. 2009;458(7239):780-3.

11. de The H, Chen Z. Acute promyelocytic leukaemia: novel insights into the mechanisms of cure. Nat Rev Cancer. 2010; 10(11):775-83.

12. Piccirillo SG, Reynolds BA, Zanetti N, Lamorte G, Binda E, Broggi G, Brem H, Olivi A, Dimeco F, Vescovi AL. Bone morphogenetic proteins inhibit the tumorigenic potential of human brain tumour-initiating cells. Nature. 2006;444(7120): $761-5$.

13. Shah MM, Landen CN. Ovarian cancer stem cells: are they real and why are they important? Gynecol Oncol. 2014;132(2):483-9.

14. Flesken-Nikitin A, Hwang CI, Cheng CY, Michurina TV, Enikolopov G, Nikitin AY. Ovarian surface epithelium at the junction area contains a cancer-prone stem cell niche. Nature. 2013;495(7440):241-5.

15. Gilks CB, Irving J, Kobel M, Lee C, Singh N, Wilkinson N, McCluggage WG. Incidental nonuterine high-grade serous carcinomas arise in the fallopian tube in most cases: further evidence for the tubal origin of high-grade serous carcinomas. Am J Surg Pathol. 2015;39(3):357-64.

16. Sherman-Baust CA, Kuhn E, Valle BL, Shih Ie M, Kurman RJ, Wang TL, Amano T, Ko MS, Miyoshi I, Araki Y, et al. A genetically engineered ovarian cancer mouse model based on fallopian tube transformation mimics human high-grade serous carcinoma development. J Pathol. 2014;233(3):228-37.
17. Burgos-Ojeda D, Rueda BR, Buckanovich RJ. Ovarian cancer stem cell markers: prognostic and therapeutic implications. Cancer Lett. 2012;322(1):1-7.

18. Ffrench B, Gasch C, O'Leary JJ, Gallagher MF. Developing ovarian cancer stem cell models: laying the pipeline from discovery to clinical intervention. Mol Cancer. 2014;13:262.

19. Oates JE, Grey BR, Addla SK, Samuel JD, Hart CA, Ramani VA, Brown MD, Clarke NW. Hoechst 33342 side population identification is a conserved and unified mechanism in urological cancers. Stem Cells Dev. 2009;18(10):1515-22.

20. Rizzo S, Hersey JM, Mellor P, Dai W, Santos-Silva A, Liber D, Luk L, Titley I, Carden CP, Box G, et al. Ovarian cancer stem cell-like side populations are enriched following chemotherapy and overexpress EZH2. Mol Cancer Ther. 2011;10(2):325-35.

21. Hu L, McArthur C, Jaffe RB. Ovarian cancer stem-like sidepopulation cells are tumourigenic and chemoresistant. $\mathrm{Br} \mathrm{J}$ Cancer. 2010;102(8):1276-83.

22. Wei Z, Lv S, Wang Y, Sun M, Chi G, Guo J, Song P, Fu X, Zhang S, Li Y. Biological characteristics of side population cells in a self-established human ovarian cancer cell line. Oncol Lett. 2016;12(1):41-8.

23. Ling H, Fabbri M, Calin GA. MicroRNAs and other non-coding RNAs as targets for anticancer drug development. Nat Rev Drug Discov. 2013;12(11):847-65.

24. Hanahan D, Weinberg RA. Hallmarks of cancer: the next generation. Cell. 2011;144(5):646-74.

25. Hayes J, Peruzzi PP, Lawler S. MicroRNAs in cancer: biomarkers, functions and therapy. Trends Mol Med. 2014; 20(8):460-9.

26. Yang Y, Li X, Yang Q, Wang X, Zhou Y, Jiang T, Ma Q, Wang YJ. The role of microRNA in human lung squamous cell carcinoma. Cancer Genet Cytogenet. 2010;200(2):127-33.

27. Haldrup C, Kosaka N, Ochiya T, Borre M, Hoyer S, Orntoft TF, Sorensen KD. Profiling of circulating microRNAs for prostate cancer biomarker discovery. Drug Deliv Transl Res. 2014; 4(1):19-30.

28. Chaluvally-Raghavan P, Jeong KJ, Pradeep S, Silva AM, Yu S, Liu W, Moss T, Rodriguez-Aguayo C, Zhang D, Ram P, et al. Direct upregulation of STAT3 by microRNA-551b-3p deregulates growth and metastasis of ovarian cancer. Cell Rep. 2016; 15(7):1493-504.

29. Lin S, Gregory RI. MicroRNA biogenesis pathways in cancer. Nat Rev Cancer. 2015;15(6):321-33.

30. Zhou JN, Zeng Q, Wang HY, Zhang B, Li ST, Nan X, Cao N, Fu CJ, Yan XL, Jia YL, et al. MicroRNA-125b attenuates epithelialmesenchymal transitions and targets stem-like liver cancer cells through small mothers against decapentaplegic 2 and 4. Hepatology. 2015;62(3):801-15.

31. Jones MF, Hara T, Francis P, Li XL, Bilke S, Zhu Y, Pineda M, Subramanian M, Bodmer WF, Lal A. The CDX1-microRNA-215 axis regulates colorectal cancer stem cell differentiation. Proc Natl Acad Sci USA. 2015;112(13):E1550-8.

32. Li C, Ding H, Tian J, Wu L, Wang Y, Xing Y, Chen M. Forkhead box protein $\mathrm{C} 2$ promotes epithelial-mesenchymal transition, migration and invasion in cisplatin-resistant human ovarian cancer cell line (SKOV3/CDDP). Cell Physiol Biochem. 2016;39(3):1098-110.

33. Zhan Q, Wang C, Ngai S. Ovarian cancer stem cells: a new target for cancer therapy. Biomed Res Int. 2013;2013:916819.

34. Yalcin S, Zhang X, Luciano JP, Mungamuri SK, Marinkovic D, Vercherat C, Sarkar A, Grisotto M, Taneja R, Ghaffari S. Foxo3 is essential for the regulation of ataxia telangiectasia mutated and oxidative stress-mediated homeostasis of hematopoietic stem cells. J Biol Chem. 2008;283(37):25692-705. 
35. Li H, Zhang Y, Zhang Y, Bai X, Peng Y, He P. TRIM31 is downregulated in non-small cell lung cancer and serves as a potential tumor suppressor. Tumour Biol. 2014;35(6):5747-52.

36. Watanabe M, Tsukiyama T, Hatakeyama S. TRIM 31 interacts with p52(Shc) and inhibits Src-induced anchorage-independent growth. Biochem Biophys Res Commun. 2009;388(2):422-7.

37. Lengyel E. Ovarian cancer development and metastasis. Am J Pathol. 2010;177(3):1053-64.

38. Tan DS, Agarwal R, Kaye SB. Mechanisms of transcoelomic metastasis in ovarian cancer. Lancet Oncol. 2006;7(11):925-34.

39. Boesch M, Zeimet AG, Reimer D, Schmidt S, Gastl G, Parson W, Spoeck F, Hatina J, Wolf D, Sopper S. The side population of ovarian cancer cells defines a heterogeneous compartment exhibiting stem cell characteristics. Oncotarget. 2014;5(16): 7027-39.

40. Szotek PP, Pieretti-Vanmarcke R, Masiakos PT, Dinulescu DM, Connolly D, Foster R, Dombkowski D, Preffer F, Maclaughlin DT, Donahoe PK. Ovarian cancer side population defines cells with stem cell-like characteristics and Mullerian Inhibiting Substance responsiveness. Proc Natl Acad Sci USA. 2006;103(30): 11154-9.

41. Beck B, Blanpain C. Unravelling cancer stem cell potential. Nat Rev Cancer. 2013;13(10):727-38.

42. Nam EJ, Yoon H, Kim SW, Kim H, Kim YT, Kim JH, Kim JW, Kim S. MicroRNA expression profiles in serous ovarian carcinoma. Clin Cancer Res. 2008;14(9):2690-5.

43. Zhou X, Hu Y, Dai L, Wang Y, Zhou J, Wang W, Di W, Qiu L. MicroRNA-7 inhibits tumor metastasis and reverses epithelialmesenchymal transition through AKT/ERK1/2 inactivation by targeting EGFR in epithelial ovarian cancer. PLoS One. 2014;9(5):e96718.

44. Tang H, Yao L, Tao X, Yu Y, Chen M, Zhang R, Xu C. miR-9 functions as a tumor suppressor in ovarian serous carcinoma by targeting TLN1. Int J Mol Med. 2013;32(2):381-8.

45. Boac BM, Xiong Y, Marchion DC, Abbasi F, Bush SH, Ramirez IJ, Khulpateea BR, Clair McClung E, Berry AL, Bou Zgheib N, et al. Micro-RNAs associated with the evolution of ovarian cancer cisplatin resistance. Gynecol Oncol. 2016;140(2):259-63.

46. He Y, Wu AC, Harrington BS, Davies CM, Wallace SJ, Adams MN, Palmer JS, Roche DK, Hollier BG, Westbrook TF, et al. Elevated CDCP1 predicts poor patient outcome and mediates ovarian clear cell carcinoma by promoting tumor spheroid formation, cell migration and chemoresistance. Oncogene. 2016;35(4):468-78.

47. Wan YW, Mach CM, Allen GI, Anderson ML, Liu Z. On the reproducibility of TCGA ovarian cancer microRNA profiles. PLoS One. 2014;9(1):e87782.

48. Xu X, Wells A, Padilla MT, Kato K, Kim KC, Lin Y. A signaling pathway consisting of miR-551b, catalase and MUC1 contributes to acquired apoptosis resistance and chemoresistance. Carcinogenesis. 2014;35(11):2457-66.

49. Levanon K, Sapoznik S, Bahar-Shany K, Brand H, ShapiraFrommer R, Korach J, Hirsch MS, Roh MH, Miron A, Liu JF, et al. FOXO3a loss is a frequent early event in high-grade pelvic serous carcinogenesis. Oncogene. 2014;33(35):4424-32.

50. Sugiura T, Miyamoto K. Characterization of TRIM31, upregulated in gastric adenocarcinoma, as a novel RBCC protein. J Cell Biochem. 2008;105(4):1081-91. 